\title{
Creating, Curating and Supporting the Wall-Less Classroom
}

\author{
Katie O'Connor \\ RCSI, Dublin, Ireland
}

\begin{abstract}
The arrival of COVID19 highlighted how ill prepared we were for the pandemic. During this period educators had no option but to trade in their cement four walled classrooms for a computer as they switched from standing at a podium in a lecture room to sitting at their kitchen table in front of their laptop presenting courses from the safety of their own homes. For many this was a gift and a curse, as working from home became the new norm. In light of the current pandemic, the demands for online education is soaring. During the COVID19 pandemic we all had to adapt and, in many cases, re-imagine how best to utilize online and hybrid learning in order to provide a safe and supportive space for learners to engage in education. This paper will illustrate how to make the most of online education as we share lessons learnt from our five year project undertaken on how to improve the Virtual Learning Environment (VLE) in a specific university, namely the VLE of the Royal College of Surgeons of Ireland (RCSI). Improvements made to the VLE as well as recommendations will be provided on how to make VLEs more user friendly and engaging.
\end{abstract}

\section{Introduction}

Historically, online learning platforms may not have been sufficiently represented in educational institutions. However nowadays, e-learning management systems are used in most universities throughout the world. Technology has been key to keeping us connected during the COVID19 pandemic as digital transformation has accelerated [1].

Online learning in combination with remote working is this year's mass experiment; the impact of which is not yet realized. The year 2020 demonstrated how we utilize digital technologies and has marked a shift in the way we view them. In the educational setting, VLE has accommodated remote learning and teaching during the different COVID19 phases and restrictions. Yet there are implications in this reliance on VLEs as educators and learners adapt to this environment.

Research [2] shows that e-learning platforms can aid students in becoming more active learners if they actively participate in the online learning process. Weng et al. [3] defines e-learning as "the use of emerging information and communication technology, especially the internet, to improve or enable education."

Universities are faced with having to choose the VLE that best suits the needs of staff and students. This study looks specifically at the usability of Moodle, this project was conducted in the RCSI and, it's primary VLE is Moodle.

\section{Literature review}

The influence a Moodle environment has on the interactive engagement of the students and teachers is considered to be an area of research that requires further investigation. In 2002, Martin Dougiamas introduced the Modular ObjectOriented Dynamic Learning Environment which is most commonly referred to by its acronym Moodle [4]. Since its origins Moodle has undergone numerous upgrades. In June 2020 version 3.9 of Moodle was rolled out with over 1,600 plugins to allow for optimal usage of Moodle's features [5].

The manner in which a VLE is used is at the discretion of the university as VLEs support a number of instruction strategies from flipped classroom, distance to blended learning. Educators face new challenges and decisions as they must determine which curriculum content is best delivered as a flipped classroom and which content would benefit from being chunked and delivered in a large online lecture setting.

Some universities and educators are coming to the realization that the current online learning environment they are using is unable to accommodate the new demands asked of it. In many cases this means re-thinking the instructional approaches taken to 
course delivery. Following the confirmation of the instructional means of the course delivery, content must be created and curated for the VLE.

Content created for Moodle and resources curated should be designed to act as a tailored library for that specific course curriculum. To engage students in online learning a multitude of techniques are available to educators. Educators may opt to use multimedia learning software, apps and gamification.

Online learning platforms play an ever-growing important role in modern education. The education field has been buzzing with ways to adapt to teaching in a COVID19 world and all that entails from practicing social distancing; limiting student occupancy in the physical classroom and reenvisaging the delivery of curriculums as we embrace technology when faced with these challenges.

In a digitally-mediated world, educators need to develop and reflect on how we think about VLEs, teach, and assess in this arena. When transferring to the online virtual platforms we must consider if this mode of education delivery comes at the cost of social engagement. To curve these potential deficiencies or lack of social interaction, team-based learning approach should be promoted as part of the online education.

It is at the discretion of the educational institution in how they wish to engage with the Virtual learning system, Moodle. Our study suggests that the institute and by extension the educators view Moodle in the following four ways:

1) Moodle can be considered "a supportive tool for blended learning environments" [4].

2) It supplements students' learning experience and reinforces didactic teaching.

3) It may be the sole means of delivering a course.

4) It acts as a database or repository that enables users to access learning materials.

The manner in which Moodle is viewed is similar to the way in which lecturers navigate and utilize Moodle. The different types of lectures attitude and interact with Moodle can be grouped into the following categories:

1) Traditional didactic educators who would have little engagement with Moodle.

2) Educators who view VLEs as merely content repository and acknowledge that e-learning could provide secondary supportive capabilities.

3) Educators who already have a proportion of their teaching on the VLE but are not equipped in respect to resources and skillsets to provide more of the curriculum utilizing the VLE.

4) Those who have been and are accustomed to providing full course curriculums online.
Improving educators understanding and interacting with VLE is a process that requires coordinated remediation and education. We must bear in mind that for some educators, technology has not been the cornerstone of their teaching thus teaching in the new COVID19 landscape meant a steep learning curve as to how best embed technology.

Depending on the school of thought, Moodle can be viewed as a distance learning system (DLS); a learning management system (LMS) or a virtual learning environment (VLE). The terms virtual learning environment (VLE) and learning management system (LMS) are often considered interchangeable as both are computerised learning systems that comprise of an array of integrated webbased applications [6].

Distance learning system (DLS) tends to be used as a catch-all term as it refers to numerous integrated combinations of information and communication technologies (ICT) and other educational technologies used to support teaching. The distance referred to in the distance learning system (DLS) title can refer to either the space and/or time existing between the parties involved in the learning process.

Regardless of the label placed on Moodle it is indisputable that Moodle is synonymous with software packages designed using pedagogical principles to create quality online learning [7]. It is these pedagogical principles and Moodle kinship with social constructionism that makes it well suited to creating learning communities.

We demonstrate how Moodle can assist with conducting lessons in electronic classrooms by providing synchronous and/or asynchronous lecture on its platform. The Moodle panopto integration allows for live webcasting and video recording. This integration means that the panopto feature on Moodle facilitates recording lectures.

It is important to acknowledge the difference between these means of lecture delivery:

- Asynchronous lectures do not take place in real time thus there is no class meeting time. Set timeframes are given to students to complete course work and exams. The asynchronous online learning environment tends to be favored by students with time constraints or busy schedules [8].

- Whilst in synchronous lectures, the lecturer and students are required to interact online simultaneously. A synchronous lecture is similar to a webinar as it enables participants to interact through text, video or audio chat from a distance in real time. In real time teaching or synchronous sessions there are numerous challenges as learners and lecturers alike experience the frustration of being kicked in and out of these teaching sessions. 
Looking forward to the phased re-opening of university campuses and resumption of limited classroom teaching sessions, we are faced with the new challenge of providing a combination of in-class and online teaching with 'blended learning' becoming the phrase of the day. As and when COVID19 restrictions ease, more face to face interactions will be permitted thus hybrid and blended lectures will become an option as it allows for a combination of inperson and online teaching.

There remains some uncertainty if blending learning will lend itself best to operating in this climate in which a proportion of in-classroom teaching shall be provided along with virtual learning facilities.

Practitioners of blended learning encounter challenges on how to cater to students' individual needs and to increase their motivational involvement with the system. Furthermore, if the notion of COVID19 becomes a thing of the past with time and a vaccination, how then will curriculum delivery change again? To ensure that we are prepared for all eventualities, contingency and scenario planning is clearly required.

\section{Aim and objectives}

This study aims to identify effective ways of utilizing an e-learning platform and improve teaching online in doing so we also explore how social engagement and support can be fostered on the Moodle platform.

\section{Methods}

The participants in this study are the RCSI undergraduate medical students. From 2015 to 2019 students were invited to complete an anonymous hard copy questionnaire on their Moodle experience for a module ( $\mathrm{n}=1,320$ in total).

In 2015 prior to the Moodle overhaul stakeholder meetings $(n=20)$ were carried out in order to better understand how the VLE can assist with curriculum delivery.

Monitoring and interpreting the activities as well as the feedback of Moodle users highlighted the areas that needed to be addressed.

\section{Discussion}

In the case of the RCSI much of the foundation for further embracing e-learning had already been laid due to the 2015-2019 departmental Moodle revamp project. We conducted an audit and quality review of our 2015 Moodle; feedback was garnered from the virtual learning platform users (i.e. students and staff). By the end of 2015, a major overhaul of the virtual learning pages and framework were carried out.

\subsection{Computer literacy}

Given the relative ubiquity of VLEs in our society in 2020, it is assumed that navigating VLEs is second nature for people. Even internet-connected populations sometimes display a lack of skills, opportunity, and environment to use e-learning to its fullest potential. This brings us onto the point of computer and information literacy.

Moving to a VLE requires the learner to possess or develop computer; information and media literacy before even approaching the subject matter itself. There is a gap between what is provided by VLEs and what users can access which is dependent upon their computer literacy. Meaning that Moodle users need to possess analytic information skills and contextspecific understanding of the VLE platform and the course subject matter.

\subsection{Social factor and sense of community online}

Staying apart and learning together is a struggle even with the help of e-learning. Encouraging student collaboration while social distancing is difficult as inperson teaching interactions don't always translate to the online setting. In a traditional classroom setting made of cement walls you can see if a student gets up and walks out of the lecture theatre.

Online classrooms cannot provide the same instinct insight but with online polls it offers lecturers the capability to establish whether or not students are 'still in the room' at different points of the online teaching session.

One of the challenges with e-learning is how can we facilitate a virtual learning environment that emulates the sense of being on a physical university campus and the feeling of being part of a wider learning community. 'You are on mute' words we hear at every online teaching session as the presenter gets to grips with the e-learning tools but for many students they constantly feel they are on mute as a lack of student community can led to the students feeling isolated and taking a passive role. Thus, these online lectures and educational videos simply become nothing more than white noise. That is why summative online assessment are used at the end of students viewing a series of educational videos; the quiz promotes greater student engagement and promotes the internalizing of learning.

As documented by $\mathrm{PhD}$ researchers there is a 'loneliness to long-distance learning' [9]. For students online learning can create a feeling of isolation. Learning is a social activity and we often focus on the lecturer / learner dynamic; and the relationship between the learner and the content. As a result, often the relationship between learners themselves is forgotten. In these range of different interactions, it is 
important for learners to feel a sense of community [10].

VLEs can be used to promote peer engagement amongst students by using blogs; wikis and discussion boards to foster social engagement. The virtual learning environment can be difficult terrain particularly when negotiating how best to translate collaborative learning to the online platform.

Achieving the balance of staying apart physically whilst learning together and collaborating virtually is challenging. E-learning can be further facilitated by providing social support to students online with peer engagement by using discussion boards and forums. Often it is preferred if social interactions are not recorded but instead conducted informally online via discussion boards; forums and chat rooms.

\subsection{Humanizing online learning}

Fundamentals to humanizing the online learning experience includes firstly turning on your camera and allowing others to see that there is another human being at the end of the line.

When using a video function, educators and learners should attempt to make eye contact even if they are only looking into a camera lens, it still provides the feeling of engagement and connectivity.

If video lecture delivery is not feasible then users should at least identify themselves with their name and photo when interacting online as it allows online interactions to feel more akin with traditional in person interactions.

Educators struggle to humanize remote teaching and learning, so too do students struggle to be seen as more than just another faceless username online. Thus, efforts should be made to create a social presence online in all interactions among students and attempts made to humanize staff- student interactions.

Moodle should enable "students to project themselves as 'real people' in an online learning community" [10]. Not only do we have to adapt our teaching for learning online, but we also have to shift the way in which we think about classroom culture and peer support on a VLE platform. It is vital to promote involvement through social student networks as well as the exchange of knowledge and information online in the VLE setting.

The manner in which we conduct ourselves online has highlighted the significance of digital professionalism [11]. During the COVID19 pandemic many students have reported struggling to get and maintain motivation which can act as an obstacle for students engaging fully in online classes. As a result, students are required more and more to be selfdirected and self-motivated learners.

\section{Results}

Prior to the 2015 Moodle overhaul, $75 \%$ of students surveyed noted that the Moodle content, interface and usability was poor. Improvements were made to the service and content quality of the VLE, following the 2015 overhaul students reported greater engagement with Moodle and higher satisfaction levels.

In the months and years following the Moodle revamp there was a sharp rise in the number of staff and students interfacing with the new and improved Moodle. Student numbers on the module remained consistent from year to year whilst the Moodle user numbers climbed annually. The only periods in the year with low Moodle traffic was the summer and Christmas holiday when students and staff were on break as shown in Figure 1.

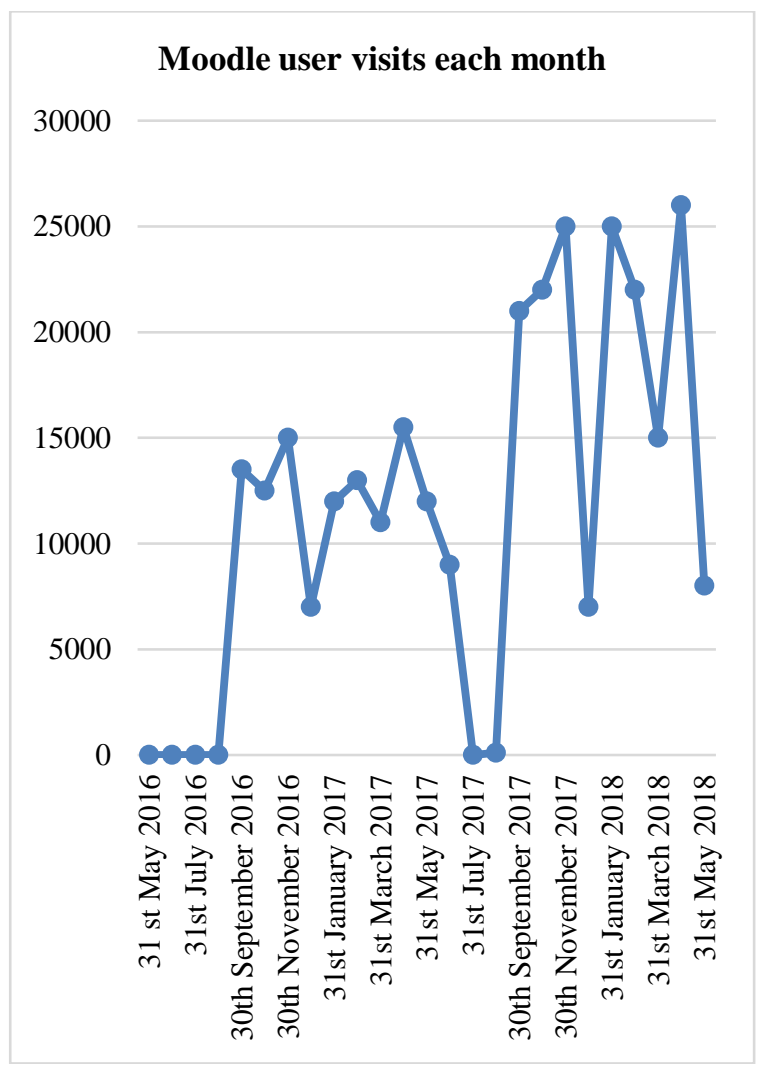

Figure 1. Moodle user traffic

Spanning from 2015 to 2019 this study looks at the use of Moodle to support students' learning. Prior to the 2015 Moodle revamp, student engagement with Moodle was low, with many students not using it at all. In 2015, survey findings showed that students viewed Moodle as portraying static content.

Moodle users' feedback was acted upon to better facilitate the learning process [12]. In the following four years additional amendments were made to further student and staff feedback. In 2019, the following three significant additions were made: 
- Turn-it-in: Introduction of turn-it-in for assignments was enabled to check for plagiarism on student paper submissions and promote student scholarship.

- Clinical scenarios: Clinical scenarios and cased based discussion along with questions were introduced onto the VLE. The use of virtual patients allowed students to experience clinical decision-making in a safe environment and to learn about rare clinical presentations [13].

- Educational videos: Introduction of a suite of 20 medical educational videos were used to replace and / or support didactic lectures.

The 2015 revamp resulted in students being able to find and access educational material easier on the more user friendly VLE. By 2018 following implementation of platform improvements, there was a $79 \%$ increase in student visits. Our study's findings indicated that using Moodle may have the potential to enhance students' learning outcomes. Findings showed that Moodle aided the overall learning experience in the following ways by creating:

- information value adding,

- knowledge value adding,

- creativity value adding and

- multimedia value adding.

The goal for us, as educators, was to establish a Moodle that users wished to access and inhabit. An online learning environment that allows flexibility of access and encourages self-directed learning.

\subsection{Improvements already implemented to our Moodle pages}

The following Moodle improvements were made which allowed for it to be further utilized:

$>$ Making a more user-friendly e-learning platform in terms of usability, layout and organization.

$>$ Improved ease of navigation.

$>$ Improved compatibility across interfaces for better access on mobile devices.

$>$ Improved diversity by creating multimedia content allowing users to select the media options that best suit their learning needs.

$>$ A suite of medical educational videos was created to demonstrate how to conduct a physical exam, take patient history, and communicate and interact with patients and their parents.

$>$ The introduction of formative selfadministered quizzes relating to the video content to enable students to take more accountability for their learning. Formative Moodle assessments were created and completed by students for each section of the module so that they could monitor their own progress and understanding of the material.

\subsection{Recommendations}

6.2.1. The social factor. Students socializing and well-being are factors that need to be considered and accommodated on the virtual learning platform. This generation of students created the phrase 'fear of missing out (FOMO)' with the acronym 'FOMO' being commonplace in their vocabulary [14]. With this in mind how can educators minimize students FOMO of the physical classroom experience and social interaction with their fellow students and staff. In addition to universities being tasked with presenting a VLE capable of operating in the COVID19 landscape, we as educators must consider how best to emulate the sense of being on-campus and in the classroom.

From 2015 to 2019, our Moodle review found that the level of interactivity was low as the Moodle forum was solely utilized by staff despite students being encouraged to engage with the forum, they opted not to. In 2016, a student specific forum on Moodle was piloted yet no students availed of this facility either. Our study found that students on Moodle were active learners as they progressed through the Moodle content, completing both voluntary and mandatory Moodle assessments. Yet students were being passive in respect to how they communicated on the platform both with staff and classmates.

The lack of sense of community on Moodle needs to be addressed as other studies $[9 ; 10]$ have shown that social inclusion is a key determinant of a student's success in online education. Without social interaction on Moodle students may feel disconnected, isolated and removed from their education.

6.2.2. Promote user engagement. Though not currently being utilized on the VLE platform, gamification may be useful for promoting student engagement and learning specific aspects of the curriculum. Gamification refers to the use of game elements and game design in non-game contexts [15]. Sinnott and Xia [15] found that Moodle Level Up has the potential to enhance learner engagement. Kohnke [16] notes that most users feel motivated and stimulated by gamified elements. Gamification has the potential to enhance the learning process in terms of results obtained by students and the enjoyability of the learning process.

6.2.3. Timely feedback and open communication. Further interaction between users particularly in respect to assessment and timely assessment feedback was found to be of great importance to students. By optimizing the use of Moodle online quizzes and selfchecking Turnitin assessments students are provided with instant feedback on their progress and understanding of the learning material. 


\section{Conclusion}

Never more so than now is the need for synergy of technology, teaching and learning. This study's findings and recommendations can contribute to how Moodle is incorporated into courses to better facilitate users' learning. We need to embrace e-learning as we remotely educate together.

Learners' experience with VLE and how educators engage with Moodle following the revamp is the focus of this study. In order to best utilize VLEs educators and learners need to familiarize themselves with the platform and its capabilities. For us to understand and grasp the educational value of VLEs there needs to be a change of direction starting with how educators utilize VLEs. Educators should establish teaching strategies that are compatible with the VLEs functions as well as developing techniques which promote engagement and aid in building an online classroom community. Moodle grounding is in social constructionism which means that it was created on the basis of promoting community learning and encouraging open communication on its platform. Therefore, it is able to adapt to both the educational and social needs of its users.

By synthesizing what we have learnt from this study it informs us of best practices and strategies when using VLEs. The year 2020 highlighted the importance of VLEs being able to provide synchronous; asynchronous and blended teaching options. The Moodle panopto integration allowed for additional features to be embedded within the VLE videos and the course material on the platform.

Being versatile is an essential feature of Moodle, it's ever expanding collection of 1,600 plugins means that Moodle has reaching capabilities. Our study did not examine the Moodle level up plugin which promotes gamification in learning, yet future research could explore this form of learning to explore the impact it may have on student motivation and online engagement levels. That said, we did note that gamification may not be deemed a compatible form of teaching and learning in certain courses as gamification tends to be most successful when learning a new language and vocabulary.

\section{References}

[1] Wade, M., and Shan, J. (2020). Covid-19 Has Accelerated Digital Transformation, but May Have Made It Harder Not Easier. MIS Quarterly Executive, 19(3), 7.

[2] Šumak, B., Heričko, M., Pušnik, M., and Polančič, G. (2011). Factors affecting acceptance and use of Moodle: An empirical study based on TAM. Informatica, 35(1).

[3] Weng, C., Otanga, S., Christianto, S. M., and Chu, R. J. C. (2020). Enhancing students' biology learning by using augmented reality as a learning supplement. Journal of Educational Computing Research, 58(4), 747-770.
[4] MoodleDocs (2019). Newsfeed on docs.Moodle.org. Retrieved 2nd November 2019.

[5] Moodle plugins directory (2020). Moodle.org. Retrieved 1 June 2020.

[6] Forment, M., Guerrero, J. C. (2008). MOODLBILE: Extending Moodle to the Mobile On/Offline Scenario. In IADIS International Conference on Mobile Learning.

[7] Brandl, K. (2005). Are You Ready to "MOODLE"? Language Learning and Technology, 9(2), 16-23. https://doi.org/10.5449/idslu-001091490.75.

[8] Rehman, R., and Fatima, S. S. (2020). An innovation in Flipped Class Room: A teaching model to facilitate synchronous and asynchronous learning during a pandemic. Pakistan Journal of Medical Sciences, 37(1).

[9] Cantor, G. (2020). The loneliness of the long-distance (PhD) researcher. Psychodynamic Practice, 26(1), 56-67.

[10] Greyling, F. C., and Wentzel, A. (2007). Humanizing education through technology: Creating social presence in large classes. South African Journal of Higher Education, 21(4), 654-667.

[11] Gabbard, G. O. (2019). Digital professionalism. Academic Psychiatry, 43(3), 259-263.

[12] Phoong, S. Y., Phoong, S. W., and Phoong, K. H. (2020). The Effectiveness of Frog Virtual Learning Environment in Teaching and Learning Mathematics. Universal Journal of Educational Research, 8(3B), 16-23.

[13] Agyeman, M. O., Cui, H., and Bennett, S. (2019). Enhancing Student Engagement in Multidisciplinary Groups in Higher Education. In International Conference on Informatics in Schools: Situation, Evolution, and Perspectives (pp. 210-221). Springer, Cham.

[14] Hodkinson, C. (2019). 'Fear of Missing Out'(FOMO) marketing appeals: A conceptual model. Journal of Marketing Communications, 25(1), 65-88.

[15] Sinnott, M., and Xia, L. A. (2020). A Review of the Moodle Gamification Plugin "Level Up": Using a Moodle Plugin to Gamify Learning of Academic Vocabulary. International Journal of Computer-Assisted Language Learning and Teaching (IJCALLT), 10(3), 89-95.

[16] Kohnke, L. (2020). Exploring Learner Perception, Experience and Motivation of Using a Mobile App in L2 Vocabulary Acquisition. International Journal of ComputerAssisted Language Learning and Teaching (IJCALLT), 10(1), 15-26. 